
poda visando ao consumo in natura. Horticultura Brasileira 25: 149-153.

\title{
Produção de tomate italiano (saladete) sob diferentes densidades de plantio e sistemas de poda visando ao consumo in natura ${ }^{1}$
}

\author{
Adriana Q Machado ${ }^{2}$; Marco Antônio R Alvarenga ${ }^{3}$; Carlos Eduardo T Florentino ${ }^{3}$ \\ ${ }^{2}$ Univag Centro Universitário, Av. Dom Orlando Chaves, 2655, Cristo Rei, 78118-000 Várzea Grande-MT; ${ }^{3}$ UFLA, Dep ${ }^{\text {to }}$ Agricultura, C \\ Postal 37, 37200-000 Lavras-MG; diquixabeira@terra.com.br; marcoant@ufla.br
}

\section{RESUMO}

Verificou-se o efeito de três espaçamentos entre plantas e três sistemas de poda sobre a produção de frutos de tomateiro do tipo italiano (saladete), visando ao consumo in natura. O delineamento experimental foi blocos ao acaso, com três repetições. Os tratamentos foram dispostos em parcelas subdivididas, com os híbridos Heinz 9780 e Kátia alocados às parcelas e, um fatorial de três espaçamentos entre plantas $(20 ; 35$ e $50 \mathrm{~cm})$ e três números de cachos por planta (2; 4 e 8), às subparcelas. As plantas foram conduzidas sem tutoramento. Houve incremento da produção total e comercial com a redução do espaçamento entre plantas e com o aumento do número de cachos por planta, com interação significativa entre essas duas variáveis, que apresentaram produção total e comercial de 202,6 t ha $^{-1}$ e 165,9 h ha $^{-1}$ respectivamente no espaçamento entre plantas de $20 \mathrm{~cm}$ e em plantas conduzidas com oito cachos. Apenas o híbrido Kátia apresentou redução significativa do número de frutos por planta quando o espaçamento entre plantas foi reduzido de $50 \mathrm{~cm}$ para 35 $\mathrm{cm}$. Houve efeito depressivo da redução do espaçamento entre plantas no peso médio de frutos, a partir de $35 \mathrm{~cm}$ para o híbrido Heinz 9780 e, 20 cm, para o híbrido Kátia. Já a poda das plantas após o segundo cacho elevou o peso médio dos frutos em $54 \%$ no híbrido Heinz 9780 e 48,6\% no híbrido Kátia, quando comparado ao tratamento com oito cachos por planta. Os resultados indicam a possibilidade de aumentar o peso médio de frutos de tomateiro com o emprego do espaçamento entre plantas de $50 \mathrm{~cm}$ para o híbrido Heinz 9780 e, 35 ou $50 \mathrm{~cm}$, para o híbrido Kátia, e da poda apical após dois ou quatro cachos. Os híbridos mostraram-se adequados para a produção de tomate destinado ao consumo in natura, por apresentarem frutos com tamanho exigido por esse mercado.

Palavras-chave: Lycopersicon esculentum Mill., espaçamento, número de cachos, peso médio de frutos.

\section{ABSTRACT}

Production of Italian tomato (saladete) in different plant densities and pruning systems aiming at in natura consumption

This experiment was carried out to study the effect of three spacings between plants and three pruning systems in the production of tomatoes, Italian class (saladete), for in natura use. Statistical procedure was based on randomized blocks with three replications, in a factorial scheme. Hybrid cultivars Heinz 9780 and Katia were planted in whole plots and the combination of three spacings between plants $(20 ; 35$ and $50 \mathrm{~cm})$ and three pruning systems resulting in 2; 4 , and 8 fruit clusters per plant, were assigned to the subplots. Plants grew without guiding. Total and commercial yield increased with plant density and with the number of fruit clusters, with significant interaction between these two variables. Total and marketable fruit yield reached their peak (202,6 and 165,9 $\mathrm{t} \mathrm{ha}^{-1}$, respectively) with $20-\mathrm{cm}$ spacing between plants and eight clusters. Hybrid Katia suffered a significant reduction in the number of fruits plant $^{-1}$ when spacing between plants was reduced from 50 to $35 \mathrm{~cm}$. The average weight of fruits was reduced when spacing between plants was bellow $35 \mathrm{~cm}$ for hybrid Heinz 9780 and bellow $20 \mathrm{~cm}$ for hybrid Katia, and increased as a result of pruning of plants after second cluster in 54,0\% for hybrid Keinz 9780 and 48,6\% for hybrid Katia. The average fruit weight can be increased with spacing between plants of $50 \mathrm{~cm}$ for hybrid Heinz 9780, and 35 or $50 \mathrm{~cm}$ for hybrid Katia and pruning after two or four fruit clusters. The hybrids performed adequately considering production of tomato for in natura consumption, with big enough fruits for market requirements.

Keywords: Lycopersicon esculentum Mill., plant spacing, number of fruit clusters, average fruit weight.

(Recebido para publicação em 4 de outubro de 2005; aceito em 12 de maio de 2007)

$\mathrm{E}$ $\mathrm{m}$ certas épocas do ano, alguns produtores têm comercializado tomates industriais, oriundos de cultivares de crescimento determinado, para consumo in natura. Algumas cultivares apresentam frutos semelhantes aos do grupo Santa Cruz e são indicadas para o mercado de fruto fresco, tais como, IPA-3 (Wanderley et al., 1980), UC-82 e Rio Grande (Pinto \& Casali, 1980) e o híbrido SM Plus F (Topseed, 1999). O potencial desses materiais para o mercado in natura foi rela- tado por Grilli et al. (2000), que encontraram cultivares com produção de até $56,2 \%$ de frutos das classes graúdo e médio, que são os mais valorizados comercialmente. Além disso, as cultivares de crescimento determinado destacam-se pelo menor custo de produção em relação às cultivares do grupo Santa Cruz, já que são conduzidas sem tutoramento, necessitam de menos desbrota, têm ciclo mais curto, e, geralmente, apresentam maior rusticidade (Alvarenga, 2004).
O grupo de tomate Saladete, também chamado de tomate italiano, é o mais novo no mercado, apresentando dupla aptidão, sendo recomendado para consumo in natura e processamento. Os frutos são alongados (7 a $10 \mathrm{~cm}$ ), com diâmetro transversal reduzido $(3$ a $5 \mathrm{~cm}$ ), biloculares, polpa espessa, coloração vermelha intensa, sendo muito firmes e saborosos (Filgueira, 2003; Alvarenga, 2004). Há no mercado cultivares com hábito de crescimento indeterminado e

${ }^{1}$ Parte da dissertação apresentada à UFLA pelo primeiro autor para obtenção do grau de mestre em Agronomia/Fitotecnia. 
determinado, sendo esta última utilizada na indústria.

Como são cultivados prioritariamente para produção de frutos para indústria, estudos relacionados ao manejo e condução das plantas com o intuito de alterar características de qualidade aparente do fruto são raros em cultivares de crescimento determinado. Já em cultivares de hábito indeterminado, há vários trabalhos que relacionam alta densidade populacional ao aumento na produção e redução no peso médio dos frutos, como demonstrado por Streck et al. (1996), ao avaliarem populações de 20; 3040 e 50.000 plantas $\mathrm{ha}^{-1}$. Os autores verificaram um aumento na produtividade comercial de frutos de tomate híbrido Monte Carlo, com o aumento da densidade de plantas, no plantio de inverno-primavera, com ponto de máxima eficiência técnica na densidade de 43.862 plantas ha ${ }^{-1}$. Observaram também uma tendência de diminuição do peso médio de frutos à medida que aumentou a densidade de plantas de 20 para 50.000 plantas ha ${ }^{-1}$. Resultados semelhantes foram obtidos por Camargos (1998), com o híbrido Carmen, e Seleguini et al. (2002), com o híbrido Duradoro, em que as produções total e comercial foram superiores no espaçamento de $30 \mathrm{~cm}$ entre plantas (33.333 plantas ha $^{-1}$ ) comparado ao espaçamento de $60 \mathrm{~cm}$ (16.666 plantas $\left.\mathrm{ha}^{-1}\right)$. O aumento da população de plantas reduziu a produção de frutos grandes, elevou a produção de frutos médios e pequenos e diminuiu o peso médio de frutos grandes e médios. Streck et al. (1998) avaliaram diferentes densidades de plantio $(20 ; 40 ; 80$ e 100.000 plantas $\mathrm{ha}^{-1}$ ) na produtividade comercial e peso médio de frutos do híbrido Monte Carlo e constataram que o aumento da densidade de plantas proporcionou aumento na produtividade comercial, principalmente entre 20 e 80.000 plantas ha-1 e redução do peso médio de frutos.

Outros trabalhos têm demonstrado a contribuição da poda apical para o aumento do peso médio de frutos. Dessa forma, Gusmão (1988) verificou para a cultivar de tomate Santa Cruz Kada, de crescimento indeterminado, que a redução do número de cachos na planta, de oito para quatro, favoreceu o aumento do peso de frutos. Segundo o au- tor, a poda apical acima do quarto cacho reduziu o número de drenos reprodutivos e vegetativos, embora a área foliar tenha mantido-se relativamente alta com o aumento no tamanho das folhas, elevando o teor de assimilados disponíveis aos frutos. Resultados semelhantes foram obtidos por Poerschke et al. (1995), com o híbrido Monte Carlo, que verificaram um maior peso médio dos frutos comercializáveis em plantas podadas para três cachos em relação às plantas conduzidas com cinco e sete cachos. Por outro lado, o número de frutos comercializáveis foi crescente com o aumento do número de cachos por planta, não havendo diferença quando conduzidas com cinco e sete cachos.

Estudos relacionados a cultivares de tomateiro de crescimento determinado, no que diz respeito à relação entre poda apical e densidade de plantio, visando estabelecer o número de cachos que resulte em frutos maiores e população de plantas adequada, tornam-se necessários a fim de que se tenha uma idéia sobre a possibilidade de utilização dessas cultivares para consumo in natura.

O objetivo deste trabalho foi verificar o efeito de três espaçamentos entre plantas e três sistemas de poda sobre a produção de frutos de tomateiro do tipo italiano (saladete), em duas cultivares de crescimento determinado, visando ao consumo in natura.

\section{MATERIAL E MÉTODOS}

O experimento foi conduzido em campo, de 7 de maio a 18 de outubro de 2002, na UFLA, em Lavras-MG ( $21^{\circ} 14^{\prime}$ 'S , 4500'W, $920 \mathrm{~m}$ de altitude). Foram utilizados os híbridos de tomate tipo italiano (saladete) Heinz 9780 e Kátia, ambos de crescimento determinado. As mudas foram produzidas em bandejas de polipropileno de 128 células contendo o substrado comercial Plantmaxâ, sendo transplantadas para o local definitivo 30 dias após a semeadura, no espaçamento de $80 \mathrm{~cm}$ entre fileiras, sendo conduzidas sem tutoramento (rasteiro). A adubação de plantio consistiu na aplicação de $500 \mathrm{~kg}$ $\mathrm{ha}^{-1}$ de $\mathrm{P}_{2} \mathrm{O}_{5}$, na forma de superfosfato simples, dez dias antes do transplante.
Foi realizada adubação de cobertura, com nitrogênio, potássio e cálcio, via fertirrigação, três vezes por semana. A adubação total de cobertura constou de $280 \mathrm{~kg}$ de N, $480 \mathrm{~kg}$ de $\mathrm{K}_{2} \mathrm{O}$ e $64 \mathrm{~kg}$ de Ca por ha, nas formas de nitrato de potássio, nitrato de cálcio e uréia, sendo distribuídas a partir do $11^{\circ}$ dia após o transplante, de acordo com a curva de absorção de nutrientes pela cultura, da seguinte forma: $7 \%$ da quantidade total de $\mathrm{N}$ e $\mathrm{K}$ na $1^{\mathrm{a}} \mathrm{e} 2^{\mathrm{a}}$ semanas, $10 \%$ na $3^{\mathrm{a} \cdot \mathrm{e}}$ $4^{\mathrm{a}}$ semanas, $13 \%$ na $5^{\mathrm{a}}$ e $6^{\mathrm{a}}$ semanas, $20 \%$ na $7^{\text {a }}$ e $8^{\text {a }}$ semanas, $25 \%$ na $9^{\text {a }}$ e $10^{\mathrm{a}}$ semanas e $25 \%$ na $11^{\mathrm{a}}, 12^{\mathrm{a}} \mathrm{e}$ $13^{\mathrm{a}}$ semanas. A cobertura com cálcio foi dividida em $20 \%$ da dose total de Ca na $5^{\text {a }}$ e $6^{\text {a }}$ semanas, $35 \%$ na $7^{\text {a }}, 8^{\text {a }}$ e $9^{\mathrm{a}}$ semanas, $45 \%$ na $10^{\mathrm{a}}, 11^{\mathrm{a}}, 12^{\mathrm{a}} \mathrm{e} \cdot 13^{\mathrm{a}}$ semanas.

O delineamento experimental adotado foi blocos ao acaso, com três repetições. Os tratamentos foram dispostos em parcelas subdivididas, sendo as parcelas representadas pelos híbridos (Heinz 9780 e Kátia) e as subparcelas pelo fatorial $3 \times 3$, sendo três espaçamentos entre plantas $(20 ; 35$ e 50 $\mathrm{cm}$ ) e três números de cachos por planta $(2 ; 4$ e 8 cachos). A parcela foi composta de duas fileiras simples de plantas, com 2,5 m de comprimento.

O controle de doenças e pragas foi efetuado de acordo com as recomendações convencionais para a cultura, utilizando fungicidas e inseticidas. $\mathrm{O}$ controle de plantas daninhas foi realizado manualmente e, as desbrotas, quando os brotos apresentavam de 3 a $5 \mathrm{~cm}$ de comprimento. A poda apical foi efetuada após o último cacho desejado. Nos tratamentos com quatro cachos por planta, foram deixados dois cachos na haste principal e dois cachos na haste correspondente à brotação axilar imediatamente abaixo do primeiro cacho, sendo as demais brotações retiradas. Nos tratamentos com dois cachos, foram eliminadas todas as brotações laterais surgidas. Os tratamentos com oito cachos corresponderam à ausência de poda apical e desbrota, e ao desenvolvimento de todas as brotações axilares. A aplicação de água foi feita pelo sistema de gotejamento, três vezes por semana, até 55 dias após o transplante e, após, diariamente até a colheita. Utilizou-se tubo gotejador modelo Rain Bird, com per- 
Tabela 1. Produção total, produção comercial, número de frutos por planta e peso médio de frutos de tomateiro, em função do híbrido, do espaçamento entre plantas e do número de cachos por planta (Total and marketable yield, number of fruits per plant and average weight of fruits of tomato plants in response to hybrids, spacing between plants and number of fruit clusters per plant). Lavras, UFLA, 2002.

\begin{tabular}{|c|c|c|c|c|c|c|c|c|}
\hline & \multicolumn{2}{|c|}{$\begin{array}{l}\text { Produção tota' } \\
\qquad \text { h ha }^{-1}\end{array}$} & \multicolumn{2}{|c|}{$\begin{array}{l}\text { Produção comercial }{ }^{1} \\
\qquad \text { h ha-1 }^{-1}\end{array}$} & \multicolumn{2}{|c|}{$\begin{array}{c}\text { Número de frutos por } \\
\text { planta }\end{array}$} & \multicolumn{2}{|c|}{$\begin{array}{c}\text { Peso médio de frutos } \\
\text { (g/fruto) }\end{array}$} \\
\hline & Heinz 9780 & Kátia & Heinz 9780 & Kátia & Heinz 9780 & Kátia & Heinz 9780 & Kátia \\
\hline \multicolumn{9}{|l|}{$\mathrm{ESP}^{2}$} \\
\hline $20 \mathrm{~cm}$ & $156,4 \mathrm{~A}$ & $120,9 \mathrm{~A}$ & $127,8 \mathrm{~A}$ & $89,6 \mathrm{~A}$ & $26,6 \mathrm{~A}$ & $21,2 \mathrm{~B}$ & $107,1 \mathrm{~B}$ & $98,8 \mathrm{~B}$ \\
\hline $35 \mathrm{~cm}$ & $87,9 \mathrm{~B}$ & $87,2 \mathrm{~B}$ & $72,6 \mathrm{~B}$ & $71,3 \mathrm{~B}$ & $24,4 \mathrm{~A}$ & $24,3 \mathrm{~B}$ & $111,1 \mathrm{~B}$ & $110,3 \mathrm{~A}$ \\
\hline $50 \mathrm{~cm}$ & $75,1 \mathrm{~B}$ & $83,5 \mathrm{~B}$ & $63,7 \mathrm{~B}$ & $68,6 \mathrm{~B}$ & $28,6 \mathrm{~A}$ & $32,6 \mathrm{~A}$ & $118,4 \mathrm{~A}$ & $113,4 \mathrm{~A}$ \\
\hline \multicolumn{9}{|l|}{$\overline{\mathrm{NCP}^{3}}$} \\
\hline 2 & $62,7 \mathrm{c}$ & $63,3 b$ & $46,9 \mathrm{c}$ & $48,8 \mathrm{~b}$ & $13,0 \mathrm{c}$ & $12,9 \mathrm{c}$ & $132,4 \mathrm{a}$ & 126,7 a \\
\hline 4 & $97,6 \mathrm{~b}$ & $81,3 b$ & $78,3 \mathrm{~b}$ & $61,3 \mathrm{~b}$ & $20,2 b$ & $19,1 \mathrm{~b}$ & $118,2 \mathrm{~b}$ & $110,7 b$ \\
\hline 8 & $159,1 \mathrm{a}$ & $146,9 a$ & $138,9 a$ & 119,4 a & $46,3 a$ & $46,1 \mathrm{a}$ & $86,0 \mathrm{c}$ & $85,2 \mathrm{c}$ \\
\hline Média & 106,5 (a) & 97,2 (a) & $88,1(\mathrm{a})$ & 76,5 (b) & $26,52(a)$ & 26,0 (a) & 112,2 (a) & $107,5(b)$ \\
\hline
\end{tabular}

Médias seguidas de mesma letra maiúscula ou minúscula nas colunas e de mesma letra minúscula entre parênteses nas linhas não diferem entre si, teste de Tukey, $\mathrm{p}<0,05$ (Means followed by the same letter, either small or capital, in the column, and the same small letter between brackets in the row, did not differ from each other, Tukey's test, $\mathrm{p}<0.05) ;{ }^{1 /}$ Frutos comerciais: frutos com diâmetro transversal maior que 33 mm e sem defeitos (Marketable fruits: fruits with transverse diameter upper than 33mm and without defects); ${ }^{2} /$ ESP: espaçamento entre plantas (ESP: spacing between plants); ${ }^{3 /}$ NCP: número de cachos por planta (NCP: number of fruit clusters per plant).

furações a cada 33 cm e vazão média de $1,5 \mathrm{~L} \mathrm{hora}^{-1}$.

Foram avaliadas as produções total e comercial de frutos, número de frutos por planta e peso médio dos frutos. Foram considerados comerciais os frutos com diâmetro transversal maior que 33 $\mathrm{mm}$ e sem defeitos (sintomas de doenças, pragas, distúrbios fisiológicos e/ou danos físicos). Os valores das características avaliadas foram submetidos à análise de variância, utilizando o aplicativo SISVAR (Ferreira, 2000). As médias foram comparadas pelo teste de Tukey a 5\% de probabilidade.

\section{RESULTADOS E DISCUSSÃO}

Houve efeito significativo dos fatores espaçamento entre plantas, número de cachos por planta e das interações espaçamento entre plantas x número de cachos por planta, e espaçamento entre plantas x híbrido sobre a produção total de frutos.

Em ambos os híbridos houve incremento da produção total quando o espaçamento entre plantas foi reduzido. Plantas com oito cachos também apresentaram maior produção (Tabela 1). Esses resultados concordam com os relatados por outros autores (Belfort, 1979; Maschio \& Sousa, 1982; Campos et al., 1987; Gusmão, 1988; Oliveira, 1993; Streck et al., 1996; Camargos, 1998; Streck et al.,

Tabela 2. Produção total de frutos de tomateiro, em função da interação entre espaçamento entre plantas e número de cachos por planta (Total yield of fruits in response to the spacing between plants and the number of fruit clusters per plant). Lavras, UFLA, 2002.

\begin{tabular}{lccc}
\hline \multirow{2}{*}{$\mathbf{N C P}^{2}$} & \multicolumn{3}{c}{$\left.\mathbf{E S P}^{\mathbf{1}} \mathbf{( c m}\right)$} \\
\cline { 2 - 4 } & $\mathbf{2 0}$ & $\mathbf{3 5}$ & $\mathbf{5 0}$ \\
\hline 2 & $85,1 \mathrm{Ac}$ & $59,5 \mathrm{Bb}$ & $44,5 \mathrm{Bb}$ \\
4 & $128,3 \mathrm{~A} \mathrm{~b}$ & $75,4 \mathrm{Bb}$ & $64,8 \mathrm{Bb}$ \\
8 & $202,6 \mathrm{Aa}$ & $127,7 \mathrm{Ba}$ & $128,7 \mathrm{Ba}$ \\
\hline
\end{tabular}

Médias seguidas de mesma letra maiúscula na linha e minúscula na coluna não diferem entre si, teste de Tukey, $\mathrm{p}<0,05$ (Means followed by the same capital letter in the rows and small letter in the columns did not differ from each other, Tukey's test, $\mathrm{p}<0.05$ ); ${ }^{1}$ ESP: espaçamento entre plantas (ESP: spacing between plants); ${ }^{2}$ NCP: número de cachos por planta (NCP: number of fruit clusters per plant).

1998), que encontraram incremento na produção total com o aumento da densidade de plantio e/ou do número de cachos por planta, em cultivares de tomate de crescimento indeterminado.

Analisando-se os resultados da interação espaçamento entre plantas $\mathrm{x}$ número de cachos por planta (Tabela 2), verificou-se que o melhor resultado para o plantio com $20 \mathrm{~cm}$ entre plantas e oito cachos por planta, responsável pela maior produção total de frutos por área obtida neste trabalho $\left(202,6 \mathrm{t} \mathrm{ha}^{-1}\right)$. Neste sentido, a competição entre plantas na maior densidade, e intraplantas, em consequiência do maior número de cachos por planta, parecem ser compensadas pelo maior número de plantas por hectare, no primeiro caso, e pela maior eficiência de cada planta quanto à produção de muitos frutos pequenos e pou- co pesados, no segundo caso, oferecendo, portanto, rendimentos semelhantes (Maschio \& Sousa, 1982).

Houve efeito do híbrido, do espaçamento entre plantas, do número de cachos por planta e das interações entre espaçamento entre plantas $\mathrm{x}$ híbrido, espaçamento entre plantas x número de cachos por planta sobre a produção de frutos comerciais. O híbrido Heinz 9780 acusou maior produção comercial de frutos em relação ao híbrido Kátia (Tabela 1), o que pode ser atribuído ao maior peso médio de seus frutos $(112,2 \mathrm{~g})$, quando comparado ao peso médio dos frutos do híbrido Kátia $(107,52 \mathrm{~g})$.

Similarmente ao ocorrido com a produção total, houve um incremento na produção comercial em função do aumento do número de cachos, bem como, maior produção registrada no menor espaçamento (Tabela 1), o que foi con- 
Tabela 3. Produção comercial de frutos de tomateiro ${ }^{1}$, em função da interação entre espaçamento entre plantas e número de cachos por planta (Marketable yield of tomato in response to the spacing between plants and number of fruit clusters per plant). Lavras, UFLA, 2002.

\begin{tabular}{lccc}
\hline \multirow{2}{*}{$\mathbf{N C P}^{3}$} & \multicolumn{3}{c}{$\mathbf{E S P}^{\mathbf{2}}(\mathbf{c m})$} \\
\cline { 2 - 4 } & $\mathbf{2 0}$ & $\mathbf{3 5}$ & $\mathbf{5 0}$ \\
\hline 2 & $60,9 \mathrm{Ac}$ & $46,9 \mathrm{ABb}$ & $35,8 \mathrm{Bb}$ \\
4 & $99,3 \mathrm{~A} \mathrm{~b}$ & $58,9 \mathrm{Bb}$ & $51,2 \mathrm{Bb}$ \\
8 & $165,9 \mathrm{Aa}$ & $110,1 \mathrm{Ba}$ & $111,3 \mathrm{Ba}$ \\
\hline
\end{tabular}

Médias seguidas de mesma letra maiúscula na linha e minúscula na coluna não diferem entre si, teste de Tukey, $\mathrm{p}<0,05$ (Means followed by the same capital letter in the rows and small letter in the columns did not differ from each other, Tukey's test, $\mathrm{p}<0.05) ;{ }^{1 /}$ Frutos comerciais: frutos com diâmetro transversal maior que $33 \mathrm{~mm}$ e sem defeitos (Marketable fruits: fruits with transversal diameter upper than $33 \mathrm{~mm}$ and without defects); ${ }^{2 /} \mathrm{ESP}$ : espaçamento entre plantas (ESP: spacing between plants); ${ }^{3 /} \mathrm{NCP}$ : número de cachos por planta (NCP: number of fruit clusters per plant).

Tabela 4. Número de frutos de tomateiro, em função da interação entre espaçamento entre plantas e número de cachos por planta (Number of fruits per plant as a function of the interaction between plant spacing and number of fruit clusters per plant). Lavras, UFLA, 2002.

\begin{tabular}{lccc}
\hline \multirow{2}{*}{$\mathbf{N C P}^{2}$} & \multicolumn{3}{c}{$\mathbf{E S P}^{\mathbf{1}}(\mathbf{c m})$} \\
\cline { 2 - 4 } & $\mathbf{2 0}$ & $\mathbf{3 5}$ & $\mathbf{5 0}$ \\
\hline 2 & $12,8 \mathrm{Ab}$ & $12,8 \mathrm{Ab}$ & $13,2 \mathrm{Ac}$ \\
4 & $19,0 \mathrm{~A} \mathrm{~b}$ & $18,7 \mathrm{Ab}$ & $21,3 \mathrm{Ab}$ \\
8 & $39,8 \mathrm{Ba}$ & $41,7 \mathrm{Ba}$ & $57,2 \mathrm{Aa}$ \\
\hline
\end{tabular}

Médias seguidas de mesma letra maiúscula na linha e minúscula na coluna não diferem entre si, teste de Tukey, $\mathrm{p}<0,05$ (Means followed by the same capital letter in the rows and small letter in the columns did not differ from each other, Tukey's test $(\mathrm{p}<0.05) ;{ }^{2} / \mathrm{ESP}$ : espaçamento entre plantas (ESP: spacing between plants); ${ }^{3 /} \mathrm{NCP}$ : número de cachos por planta (NCP: number of fruit clusters per plant).

firmado pela interação significativa entre essas duas variáveis, com maior produção comercial no espaçamento de 20 cm entre plantas e oito cachos por planta (Tabela 3).

Estes resultados concordam com os descritos por Maschio \& Sousa (1982), em que tanto a redução do espaçamento como o maior número de cachos por planta promoveram acréscimos elevados na produção comercial de frutos da cultivar Kadá, de crescimento indeterminado. Da mesma forma, Campos et al. (1987) constataram que a poda para três cachos reduziu a produção comercial de frutos da cultivar São Sebastião, de crescimento indeterminado, enquanto a redução do espaçamento elevou a produção comercial. Poerschke $e t$ al. (1995) reportaram, para o híbrido Monte Carlo, de crescimento indeterminado, que plantas conduzidas com maior número de inflorescências, independente do número de hastes, apresentam maior rendimento total de frutos comercializáveis. E, finalmente,
Camargos et al. (2000) relataram maior produção comercial de frutos da cultivar Carmem, de crescimento indeterminado, no espaçamento de $30 \mathrm{~cm}$ entre plantas e sete cachos por planta.

Houve efeito significativo do espaçamento entre plantas, número de cachos por planta e da interação entre espaçamento entre plantas $\mathrm{x}$ número de cachos por planta sobre o número de frutos por planta.

Constatou-se redução significativa do número de frutos por planta no híbrido Kátia (Tabela 1) quando se reduziu o espaçamento entre plantas de 50 $\mathrm{cm}$ para $35 \mathrm{~cm}$, repetindo resultados obtidos por outros autores (Austin \& Dunton Junior, 1970; Fery \& Janick, 1970; Maschio \& Sousa, 1982; Campos et al., 1987). Esta queda na produção individual das plantas, quando sujeitas às maiores populações, é atribuída à mudança na distribuição de assimilados como resposta a uma competição que se verifica na planta (competição espaçamento entre plantas $\mathrm{x}$ híbrido e intraplanta), agravada pela competição entre plantas (competição interplanta), comprometendo o pegamento dos frutos ou reduzindo a produção de flores por cacho (Austin \& Dunton Junior, 1970). Não foi verificada alteração significativa no número de frutos em plantas do híbrido Heinz 9780, em relação ao espaçamento entre plantas. A poda das plantas após formação de dois ou quatro cachos, resultou em redução significativa do número de frutos por planta, em ambos os híbridos (Tabela 1). Resultados semelhantes foram obtidos por Campos et al. (1987), Poerschke et al. (1995) e Seleguini et al. (2002), em cultivares de tomate de crescimento indeterminado. De acordo com os resultados da interação entre espaçamento entre plantas e número de cachos por planta, um maior número de frutos foi obtido em plantas com oito cachos no espaçamento de $50 \mathrm{~cm}$ (Tabela 4).

Houve efeito significativo do híbrido, espaçamento entre plantas e número de cachos por planta sobre o peso médio de frutos.

O peso médio dos frutos foi maior no híbrido Heinz 9780 (112,2 g) comparado ao híbrido Kátia (107,5 g) (Tabela 1). Houve efeito depressivo da redução do espaçamento entre plantas no peso médio de frutos, em ambos os híbridos (Tabela 1). O híbrido Heinz 9780 apresentou perda significativa no peso médio de frutos a partir do espaçamento $35 \mathrm{~cm}$, enquanto no híbrido Kátia esse efeito se fez presente apenas no espaçamento $20 \mathrm{~cm}$ (Tabela 1). Já a poda das plantas após a emissão do segundo cacho elevou o peso médio dos frutos em 54\% (132,4 g) no híbrido Heinz 9780 e 48,6\% (126,7 g) no híbrido Kátia, quando comparado ao tratamento com oito cachos por planta $(86,0$ e 85,2 g, respectivamente para os híbridos Heinz 9780 e Kátia). Efeito semelhante foi relatado por Campos et al. (1987), que observaram aumento de até $17 \%$ no peso médio de frutos da cultivar São Sebastião, de crescimento indeterminado, em plantas podadas após a emissão do terceiro cacho de flores, quando comparada à ausência de poda, e por Poerschke et al. (1995), que obtiveram frutos com maior peso médio também em plantas podadas após a terceira inflorescência em relação às plantas conduzidas com 
cinco e sete inflorescências. Como os frutos são drenos metabólicos fortes, os fotoassimilados foram translocados preferencialmente para esse órgão, promovendo o aumento de peso (Peluzio et al., 1995). Além disso, a poda apical acima do segundo cacho reduziu o número de drenos vegetativos e reprodutivos, embora a área foliar tenha se mantido relativamente alta com o aumento no tamanho das folhas, elevando o teor de assimilados disponíveis por fruto (Veliath \& Ferguson, 1972; Gusmão, 1988).

De um modo geral, o peso médio dos frutos obtido nesse trabalho está dentro do padrão exigido pelo mercado de frutos in natura para cultivares do tipo Santa Cruz, que é de 80 a 200 g (Alvarenga, 2000). Os valores também concordam com os relatados por Tivelli (1994), para a cultivar Santa Clara, de crescimento indeterminado, em que o peso médio dos frutos variou de 54,6 a 131,1 g, sendo o menor valor observado na classe pequeno e o maior na classe graúdo.

Os resultados indicam a possibilidade de aumentar o peso médio dos frutos de tomateiro com o emprego do espaçamento entre plantas de $50 \mathrm{~cm}$ para o híbrido Heinz 9780, e 35 ou $50 \mathrm{~cm}$ para o híbrido Kátia e da poda apical após dois ou quatro cachos. Os híbridos mostraram-se adequados para a produção de tomate destinado ao consumo in natura, por apresentarem frutos com tamanho exigido por esse mercado.

Agradecimentos

Os autores agradecem à FAPEMIG pelo financiamento parcial da pesquisa e à Eagle Comércio de Sementes Ltda, distribuidora dos híbridos de tomate BHN Seed, pelas sementes cedidas.

\section{REFERÊNCIAS}

ALVARENGA MAR. 2004. Tomate: produção em campo, casa-de-vegetação e em hidroponia. Lavras: UFLA. 400p.
ALVARENGA MAR. 2000. Cultura do tomateiro. Lavras: UFLA. 91p. (Textos Acadêmicos, 2).

AUSTIN ME; DUNTON JUNIOR EM. 1970. Fertilizer - plant population studies for once tomato harvester. Journal of the American Society for Horticultural Science 95: 645-649.

BELFORD CC. 1979. Efeito da poda da haste principal e população de plantas sobre a produção de frutos e sementes do tomateiro (Lycopersicon esculentum Mill.). Viçosa: UFV. 45p. (Tese mestrado).

CAMARGOS MI; FONTES PCR; CARDOSO AA; CARNICELLI JHA. 2000. Produção de tomate longa vida em estufa, influenciada por espaçamento e número de cachos por planta. In: CONGRESSO BRASILEIRO DE OLERICULTURA, 40., 2000, São Pedro. Horticultura Brasileira. Brasília: SOB/ UNESP-FCAV. p.563-564. (Suplemento).

CAMARGOS MI. 1998. Produção e qualidade de tomate longa vida em estufa, em função do espaçamento e do número de cachos por planta. Viçosa: UFV. 68 p. (Tese mestrado)

CAMPOS JP; BELFORD CC; GALVÃO JD FONTES PCR. 1987. Efeito da poda da haste e da população de plantas sobre a produção do tomateiro. Revista Ceres 34: 198-208.

FERREIRA DF. 2000. Análises estatísticas por meio do SISVAR para Windows versão 4.0. In: REUNIÃO BRASILEIRA DA SOCIEDADE INTERNACIONAL DE BIOMETRIA, 45., 2000, São Carlos. Programas e Resumos... São Carlos: UFScar. p.235.

FERY RL; JANICK J. 1970. Response of the tomato to population pressure. Journal of the American Society for Horticultural Science 95. 614-624.

FILGUEIRA FAR. 2003. Solanáceas: agrotecnologia moderna na produção de tomate, batata, pimentão, pimenta, berinjela e jiló. Lavras: UFLA. 331p.

GRILLI GVG; CINTRA AAD; BRAZ LT; SANTOS GM; BRAZ BA. Produtividade e classificação de frutos de tomateiro de hábito de crescimento determinado. In: CONGRESSO BRASILEIRO DE OLERICULTURA, 40. 2000, São Pedro. Horticultura Brasileira. Brasília: SOB/UNESP-FCAV, 2000. p. 727729 (Suplemento).

GUSMÃO SAL. 1988. Efeito da poda e da densidade de plantio sobre a produção do tomateiro (Lycopersicon esculentum Mill.). Viçosa: UFV. 102p. (Tese mestrado).

MASCHIO LM; SOUSA GF. 1982. Adubação básica, nitrogênio em cobertura, espaçamento e desbrota, na produção do tomateiro. Pesquisa Agropecuária Brasileira 17: 1309-1315.
OLIVEIRA VR. 1993. Número de ramos por planta, poda apical é época de plantio influenciando a produção e a qualidade dos frutos de tomateiro (Lycopersicon esculentum, Mill.) $c v$. Kadá. Viçosa: UFV. 114p. (Tese mestrado).

PELUZIO JM; CASALI VWD; LOPES NF. 1995. Partição de assimilados em tomateiro após a poda apical. Horticultura Brasileira 13: 41-43.

PINTO CMF; CASALI VWD. 1980; Clima, época de plantio e cultivares de tomateiro. Informe Agropecuário 6: 10-13.

POERSCHKE PRC; BURIOL GA; STRECK NA; ESTEFANEL V. 1995. Efeito de sistemas de poda sobre o rendimento do tomateiro cultivado em estufa de polietileno. Ciência Rural 25: $379-384$

SELEGUINI A; SENO S; ZIZAS GB. 2002. Influência do espaçamento entre plantas e número de cachos por planta na cultura do tomateiro, em condições de ambiente protegido. In: CONGRESSO BRASILEIRO DE OLERICULTURA, 42., 2002, Uberlândia. Uberlândia: SOB (CD-ROM).

STRECK NA; BURIOL GA; ANDRIOLO JL; SANDRI MA. 1998. Influência da densidade de plantas e da poda apical drástica na produtividade do tomateiro em estufa de plástico. Pesquisa Agropecuária Brasileira 33: 1105-1112.

STRECK NA; BURIOL GA; SCHNEIDER FM. 1996. Efeito da densidade de plantas sobre a produtividade do tomateiro cultivado em estufa de plástico. Pesquisa Agropecuária Brasileira 31: 105-112.

TIVELLI SW. 1952. Avaliação das práticas culturais de poda e desbrota sobre diferentes sistemas de tutotamento da cultura do tomateiro (Lycopersicon esculentum Mill.). Piracicaba: USP-ESALQ. 52p. (Tese mestrado).

TOPSEED SEMENTES. 1999. Nova geração de híbridos. Itaipava: TOPSEED.

VELIATH JA; FERGUSON AC. 1972. The effect of deblosseming fruit size, yield, and earliness in tomato. HortScience 7: 278-279.

WANDERLEY LJ; FERRAZ E; MELO PCT. 1980. IPA-3: nova cultivar de tomate (Lycopersicon esculentum Mill.) de porte determinado para consumo ao natural. Pesquisa Agropecuária Pernambucana 4: 107-112. 